\title{
A Polymer Flooding Mechanism for Mature Oil Fields: Laboratory Measurements and Field Results Interpretation
}

\author{
Ivonete PG Silva ${ }^{1 *}$ and Elizabete F Lucas ${ }^{1,2}$ \\ ${ }^{1}$ Universidade Federal do Rio de Janeiro, Instituto de Macromoléculas/LMCP, Brazil \\ ${ }^{2}$ Universidade Federal do Rio de Janeiro, COPPE/PEMM/LADPOL, Brazil
}

Submission: January 18, 2018; Published: February 06, 2018

*Corresponding author: Ivonete PG Silva, Universidade Federal do Rio de Janeiro, Instituto de Macromoléculas/LMCP, Av Horácio Macedo, 2030, block J, 21941598, Rio de Janeiro, Brazil, Email: ivonetepgs@gmail.com

Abstract

During propagation in mature fields, the polymer dispersion can undergo different concentration regimes. This change of regime in the porous medium can promote a significant reduction of the water effective permeability, making this the main mechanism of the polymer flooding process in mature fields.

Keywords: Enhanced oil recovery; Polymer flooding, Particle size, Rheology; Permeability

\section{Introduction}

Polymer flooding is an enhanced oil recovery that consists in addition of polymers with high thickening potential in the injection water [1-3]. The polymer increases the aqueous phase viscosity promoting the mobility ratio reduction and increasing the sweep efficiency. Additionally, depending on the polymer type, the effective permeability to water in the zones swept by the polymer can be reduced [4]. These are the fundamental mechanisms widely accepted.

During propagation in mature fields, the polymer dispersion preferably flows into the more permeable and washed zones, which can lead to greatly reduced concentration and viscosity of polymer dispersion. Depending on the dilution of polymer dispersion in these zones, the polymer dispersion may undergo different concentration regimes. A research based on the evaluation of hydrodynamic diameter (Dh), rheological behavior and flow tests on porous media showed that the static and thermodynamic properties of Partially Hydrolyzed Polyacrylamide (HPAM) are markedly impacted by these concentration regimes [5].

\section{Particle Size and Rheological Evaluations}

The HPAM in this study was 5-6.106 nominal molar mass and $30 \%$ hydrolysis degree. The diffusion coefficient was measured by dynamic light scattering (DLS) and introduced in the
Stokes-Einstein equation to convert to hydrodynamic size. The consistency index $(\mathrm{K})$, which represents the thickening potential, was obtained with Power-law model adjustment.

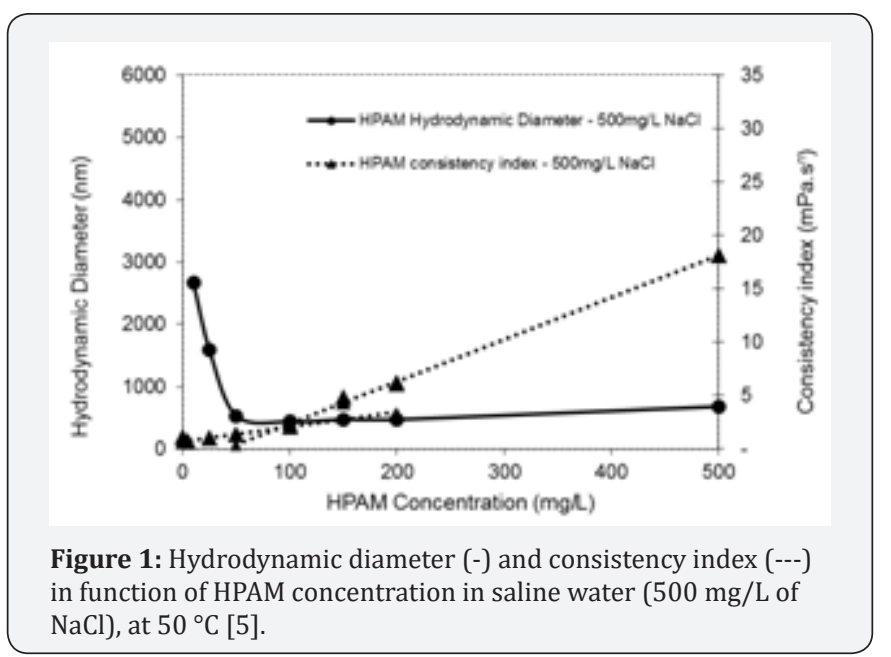

Concentration influence. The evaluation of the $\mathrm{Dh}$ and consistency index of the dispersions of HPAM in saline) solution $500 \mathrm{mg} / \mathrm{L}(\mathrm{NaCl})$ were analyzed in the range of 10 to $1000 \mathrm{mg} / \mathrm{L}$ and at temperature of $50^{\circ} \mathrm{C}$. The Dh versus concentration curves presented in Figure 1 show an inflection point at approximately $50 \mathrm{mg} / \mathrm{L}$ and the consistency index versus concentration at 100 $\mathrm{mg} / \mathrm{L}$. These values of overlapping concentration $\left({ }^{*} \mathrm{C}\right)$ marks the 
separation between the diluted and semi-diluted regime. The difference of values of ${ }^{*} \mathrm{C}$ has been reported by other authors and it has been attributed to the differences in shear applied by the two techniques, since an increase in shear causes polymer chain elongation, hindering interpenetration and increasing the value of $\mathrm{C} *$ detected [6].

The rheological analysis shows that the thickening potential $(\mathrm{K})$ of the HPAM increases markedly at concentrations greater than overlapping $\left({ }^{*} \mathrm{C}\right)$, while the hydrodynamic diameter tends to its lower value (unperturbed value).

The Dh data of the analyzed HPAM dispersions show great variation as a function of the concentration. The Dh increase was greater at lower concentrations (dilute regime), probably because the smaller the number of dispersed macromolecules:

(i) the weaker the repulsion between the macromolecules is; and

(ii) the greater the hydration is, leading to a larger hydrodynamic diameter [7].

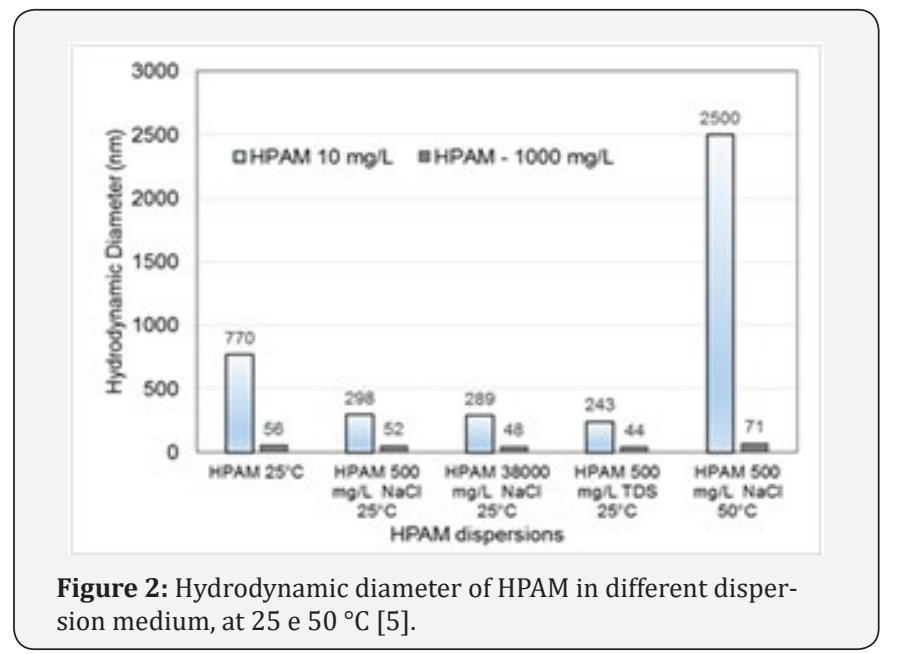

The influence of salinity and temperature on the HPAM hydrodynamic diameter is showed at Figure 2. The polymer concentrations were chosen to represent the dilute and concentrated regimes. Besides this, a softened injection water, treated to remove divalent cations $(500 \mathrm{mg} / \mathrm{L}$, Dissolved solids total) was also analyzed [8].

\section{Concentration influence}

The Figure 2 shows the dispersions of HPAM at concentration of $10 \mathrm{mg} / \mathrm{L}$ (dilute regime) had larger $\mathrm{Dh}$ than those at concentration of $1,000 \mathrm{mg} / \mathrm{L}$ (concentrated regime) under all the conditions analyzed. The increase of HPAM concentration from 10 to $1000 \mathrm{mg} / \mathrm{L}$ decreases the $\mathrm{Dh}$ from $770 \mathrm{~nm}$ to $56 \mathrm{~nm}$, at 25 ${ }^{\circ} \mathrm{C}[9]$.

\section{Salinity influence}

For both polymer concentration regimes, rising salinity caused a reduction of the $\mathrm{Dh}$. The increase of salinity $(\mathrm{NaCl})$ from
0 to $500 \mathrm{mg} / \mathrm{L}$ decrease the $\mathrm{Dh}$ from $770 \mathrm{~nm}$ to $298 \mathrm{~nm}$, at $25^{\circ} \mathrm{C}$, in dilute regime of HPAM concentration $(10 \mathrm{mg} / \mathrm{L})$. The impact of salinity increase in Dh of HPAM concentrated dispersions is little significant, as well as the salinity increase from $500 \mathrm{mg} / \mathrm{L}$ to $38000 \mathrm{mg} / \mathrm{L}$, in both concentration regime, (dilute and concentrated) at $25^{\circ} \mathrm{C}$.

\section{Temperature influence}

The temperature increase from $25{ }^{\circ} \mathrm{C}$ to $50{ }^{\circ} \mathrm{C}$ promotes intensity increase in Dh of HPAM dilute dispersions. The Dh of $10 \mathrm{mg} / \mathrm{L}$ HPAM dispersion (dilute regime) in saline solution $(500 \mathrm{mg} / \mathrm{L})$ increase from $298 \mathrm{~nm}$ to $2500 \mathrm{~nm}$ in this temperature range. This temperature difference was little significant in the Dh of HPAM concentrated dispersions. The increase temperature increase intensity the Dh of HPAM dilute dispersion and prevalence over the Dh decrease due the increase salinity.

\section{Flow in Porous Media}

\section{Artificial metallic porous media}

Silva \& Lucas [10] tested the same HPAM in artificial metallic porous media. The porous medium had permeability of 60,000 $\mathrm{mD}$, pore diameter of 15 microns and they were $100 \%$ suturated with saline solution. The dispersion of HPAM of $1000 \mathrm{mg} / \mathrm{L}$ (concentrated regime and $\mathrm{Dh} \sim 71 \mathrm{~nm}$ ) flowing in the porous medium resulted in a higher resistance factor (RF), but did not change the permeability (residual resistance factor $(\mathrm{RRF})=1$ ). While the $10 \mathrm{mg} / \mathrm{L} \mathrm{HPAM}$ dispersion (dilute regime and $\mathrm{Dh}$ $2500 \mathrm{~nm}$ ) flowing in similar porous medium promoted a lower resistance factor, but a significant residual resistance factor. The permeability reduction attributed to polymeric retention in the porous medium is the sum of the contributions of adsorption, mechanical and hydrodynamics retentions [9]. In this metallic porous media, adsorption is not expected. The hydrodynamic retention is associated to the flow and is considered to be of little significance. However, the porous media were similar and the flow rate was the same. Then, the permeability reduction could be attributed primarily to mechanical retention. The greater retention obtained with the lower concentration polymer dispersion was due to its higher hydrodynamic volume.

\section{Natural sandstone cores}

High reduction of water permeability due to flow of HPAM diluted dispersions was also observed in natural porous media in bench tests. They were also $100 \%$ saturated with saline solution.

\section{Injectivity teste in field applications}

As reported in the literature, an injectivity test in the field, with this same HPAM showed higher RRF where there was higher water production before polymer dispersion application $[7,8]$. This behavior was detected by pressure monitoring and tracer application. In this case the reduction occurred in the water effective permeability, since the porous medium (reservoir) was naturally saturated with oil and water. The mechanism of this 


\section{Recent Advances in Petrochemical Science}

result can also be credited to the expansion of the polymeric hydrodynamic volume due to dispersion dilution in diluted regime.

\section{Conclusion}

The results obtained in the analyzed conditions show that the polymeric Dh expansion due to concentration reduction in the diluted regime and the temperature increase can promotes significant mechanical retention, even in high salinity conditions. The mechanism presented favors the application of polymer flooding process in mature fields with high heterogeneity and salinity, of most economical form. The impact of concentration and temperature variation in the Dh can be expected for other flexible macromolecule systems and porous media.

\section{References}

1. De Gennes PG (1979) Scaling concepts in polymer solutions. Cornell University Press, Ithaca.

2. Kaszuba M McKnight, D Connah MT, McNeil Watson FK, Nobbmann UJ (2008) Measuring sub nanometer sizes using dynamic light scattering. J Nanopart Res 10(5): 823-829.

3. Lake LW (1989) Enhanced oil recovery. Prentice-Hall Inc, New Jersey, USA.
4. Sorbie SK (1991) Polymer-Improved Oil Recovery. CRC Press Inc.

5. Silva IPG, Aguiar AA, Resende VP, Monsores ALM, Lucas EF (2018) A polymer flooding mechanism for mature oil fields: Laboratory measurements and field results interpretation. Petroleum Science and Engineering 161: 468-475.

6. Rodd AB, Dunstan DE, Boger DV, Schmidt J, Burchard W (2001) Heterodyne and Nonergodic Approach to Dynamic Light Scattering of Polymer Gels: Aqueous Xanthan in the Presence of Metal Ions. (Aluminum (III). Macromolecules 34(10): 3339-3352.

7. Melo MA, Lins JR AG, Silva IPG (2017) Lessons Learned from Polymer Flooding Pilots in Brazil. SPE Latin America and Caribbean Mature Fields Symposium, Salvador, SPE 184956

8. Melo MA, Holleben CR, Silva IPG, Correia AC, Silva GA, et al. (2005) Evaluation of Polymer Injection Projects in Brazil (SPE 94898). In: SPE Latin America and Caribbean Petroleum Engineering Conference, Rio de Janeiro.

9. Oliveira LFL, Schiozer DJ, Delshad M (2016) Impacts of polymer properties on field indicators of reservoir development projects. Journal of Petroleum Science and Engineering 147: 346-355.

10. Silva IPG, Lucas EF (2017) New Insight on the Polymer Flooding to Mature Fields. SPE Latin America and Caribbean Mature Fields Symposium, Salvador, SPE 184907.

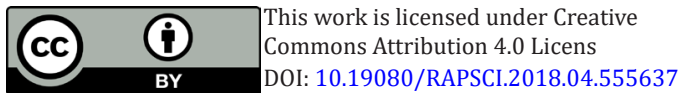

\begin{tabular}{|l|}
\hline \multicolumn{1}{|c|}{ Your next submission with Juniper Publishers } \\
will reach you the below assets \\
- Quality Editorial service \\
- Swift Peer Review \\
- Reprints availability \\
- E-prints Service \\
- Manuscript Podcast for convenient understanding \\
- Global attainment for your research \\
- Manuscript accessibility in different formats \\
( Pdf, E-pub, Full Text, Audio) \\
- Unceasing customer service \\
Track the below URL for one-step submission \\
https://juniperpublishers.com/online-submission.php \\
\hline
\end{tabular}

